\title{
Correlation Between Patient-reported Outcome Scores and Objective Functional Assessments Following Surgical Treatment of Achilles Tendon Ruptures
}

\author{
(DD Gürkan Gümüşsuyu11, (1) Mehmet Melih Asoğlu², (D) Mehmet Barış Ertan², (1) Ömer Faruk Kılıçaslan², (1) Özkan Köse² \\ 1istinye University Faculty of Medicine, Department of Orthopaedics and Traumatology, Istanbul, Turkey \\ ${ }^{2}$ Antalya Training and Research Hospital, Clinic of Orthopaedics and Traumatology, Antalya, Turkey
}

\section{Abstract}

Objective: The purpose of this retrospective study was to investigate the correlation between patient-reported outcome scores and objective functional assessments following surgical treatment of Achilles tendon ruptures (ATR).

Methods: A retrospective review of 53 patients with acute ATR who underwent primary surgical repair was performed. Patient-reported functional outcomes were evaluated with the ATR score (ATRS). Calf atrophy was assessed using the difference between the maximum calf circumference on the involved and healthy sides. The objective functional capacity of the lower leg was assessed using a single-leg standing heel-rise fatigue test. The limb symmetry index (LSI) was calculated as the ratio between the injured and uninvolved limbs. The correlation between variables was tested using the Spearman correlation test.

Results: There were 53 patients (50 males and three females) with a mean age of 40.8 \pm 7.7 years (range, 27-59 years). The mean follow-up duration was 35.6 \pm 16.6 months (range, 12-80 months). The mean ATRS ranged from 88 to 100 points with a mean of points. There was a mean of $1.15 \pm 0.6 \mathrm{~cm}$ (range, $0-2 \mathrm{~cm}$ ) calf circumference difference between the limbs. Calf atrophy was present in $46(86.7 \%)$ patients. The mean LSI (\%) was $87.5 \% \pm 9.3 \%$ (range, 61\%-100\%). No correlation was detected between the ATRS score and calf atrophy and LSI.

Conclusion: The ATRS overestimates the objective functional capacity of the Achilles tendon. New scoring systems that combine both subjective and objective measures are required to assess the overall outcome following an ATR.

Keywords: Achilles tendon rupture, surgical repair, patient-reported outcome scores, functional recovery

\section{INTRODUCTION}

Achilles tendon ruptures (ATR) are the most common tendon injuries seen in the adult population (1). They frequently occur in active young males during sporting activities. Although the exact etiology is unknown, chronic degenerative tendinopathy is the significant risk factor (2,3). An acute ATR might be managed either with surgical or conservative treatment methods. However, the optimal treatment of ATR remains controversial. Some authors advocated surgical treatment because of the decreased risk of re-rupture. Others favored conservative treatment because both treatment methods result in similar functional recovery with a lower complication rate. One of the most important reasons for obtaining different results is that the outcome scores and evaluations vary considerably among these studies (4-8).

The most popular patient-reported outcome score for evaluating Achilles tendon functions is the ATR score (ATRS). It is a simple questionnaire comprising 10 questions. Each item is rated between 0 (worst) and 10 (best) with a maximum cumulative score of $100(9,10)$. The reliability and validity of ATRS have been shown in previous studies (11-13). However, ATRS only provides 
subjective data of the patients' own opinions about the results. We hypothesized that objective and subjective assessments on the functional outcomes of ATR are variable, and patient-reported outcome measures might overestimate the actual functional capacity following surgical treatment of ATR. The purpose of this retrospective study was to investigate the correlation between residual functional deficits and patient-reported outcome scores following surgical treatment of ATR.

\section{METHODS}

\section{Patients and Study Design}

A retrospective review of patients who underwent primary repair of acute ATR in authors' institutions between 2013 and 2019 was performed. Patients treated with mini-open or closed techniques, chronic ATR admitted later than four weeks, patients who had missing clinical data and followed less than one year were excluded from the study. During the study under investigation, 67 cases were identified. Of these patients, 14 were excluded, and 53 patients were eligible for study inclusion. This research was undertaken in compliance with the ethical principles set out in the Helsinki Declaration of 1964 and its later modifications. Also, the Institutional Review Board at Antalya Training and Research Hospital approved the study protocol (approval date/ issue: 4.3.2021/1.34). All patients provided consent to participate in the study.

\section{Surgical Technique and Postoperative Rehabilitation}

All patients underwent open primary repair using either the Krakow or Kessler end-to-end suture technique with nonabsorbable sutures. A short or long leg cast was performed in the neutral position of the ankle for three weeks postoperatively, and the patients were mobilized with crutches without weight-bearing. Afterward, the cast was removed, and active ankle exercises were started without weight-bearing. Fullweight-bearing was encouraged at the end of the sixth week. Participation in recreational sporting activities was allowed after the sixth postoperative month.

\section{Functional Evaluations at the Final Follow-up}

All patients were followed for at least 12 months. At the final follow-up, the Turkish version of the ATRS was used to evaluate the patient-reported functional outcome (14). The functional capacity of the lower leg was assessed using the single-leg standing heel-rise fatigue test. The patients were asked to perform repetitive heel-rises as many and as quickly as possible until reaching fatigue. The total number of repetitions was counted and recorded. First, the healthy side and then the injured side were tested. The limb symmetry index (LSI) was calculated as the ratio between the injured and uninvolved limbs and expressed as a percentage. The maximum calf circumference was measured on both sides, and the difference was recorded as an objective measure of calf atrophy. Finally, the ankle range of motion was evaluated

\section{Statistical Analysis}

Statistical analysis was performed using SPSS Statistics Base v.23 for Windows. Descriptive statistics of the continuous and categorical data are presented as the mean \pm standard deviation, range, and frequency distribution. The Kolmogorov-Smirnov test was used to determine whether the data were distributed normally. The correlation between variables was tested using the Spearman correlation test. A value of $p<0.05$ was accepted as statistically significant.

\section{RESULTS}

There were 53 patients ( 50 males and three females) with a mean age of $40.8 \pm 7.7$ years (range, $27-59$ years). The right side was involved in 29 (54.7\%) patients and left in 24 (45.3\%) patients. The mean follow-up duration was $35.6 \pm 16.6$ months (range, 12 80 months). Superficial wound infection was seen in six (11.3\%) patients and was treated with oral antibiotics. Permanent sural nerve injury was seen in three (7.5\%) patients. Ankle dorsiflexion was limited to four patients ( $10^{\circ}$ in three and $20^{\circ}$ in one). Two (3.7\%) patients had re-rupture and underwent revision surgery. No other complications were recorded. A summary of the demographic and clinical characteristics of patients is presented in Table 1.

The mean ATRS ranged from 88 to 100 points with a mean of points. There was a mean of $1.15 \pm 0.6 \mathrm{~cm}$ (range, $0-2 \mathrm{~cm}$ ) calf

Table 1. Demographic and clinical characteristics of patients

\begin{tabular}{|l|l|l|}
\hline Variable & Mean \pm SD & Range \\
\hline Age (years) & $40.8 \pm 7.7$ & $27-50$ \\
\hline Height $(\mathrm{cm})$ & $177.3 \pm 7.3$ & $160-193$ \\
\hline Weight $(\mathrm{kg})$ & $87.2 \pm 12.5$ & $60-125$ \\
\hline BMI $\left(\mathrm{kg} / \mathrm{m}^{2}\right)$ & $27.6 \pm 2.9$ & $22.7-38.5$ \\
\hline Follow-up (months) & $35.6 \pm 16.9$ & $12-80$ \\
\hline Injured side single-leg rise test $(\mathrm{n})$ & $21.7 \pm 7.3$ & $6-38$ \\
\hline Healthy side single-leg rise test $(\mathrm{n})$ & $24.6 \pm 7.5$ & $8-40$ \\
\hline LSI (\%) & $87.5 \pm 9.3$ & $61.1-100$ \\
\hline Calf atrophy (cm) & $1.15 \pm 0.6$ & $0-2$ \\
\hline ATRS (points) & $97.6 \pm 2.4$ & $88-100$ \\
\hline Bu B Bus
\end{tabular}

BMI: Body mass index, ATRS: Achilles tendon rupture score, LSI: Limb symmetry index, SD: Standard deviation 
circumference difference between the limbs. Calf atrophy was present in 46 (86.7\%) patients. The mean LSI (\%) was $87.5 \% \pm 9.3 \%$ (range, 61\%-100\%). No correlation was detected between the ATRS score and calf atrophy, and LSI (Table 2, Figure 1). Patients were divided into two groups according to their LSI score. The first group consisted of patients who had LSI scores less than 90\%, and the second group had scores greater than $90 \%$. Although the LSI was significantly different between groups (80.6 \pm 8.6 vs. $94.2 \pm 2.9, p=0.001)$, the ATRS was similar (97.6 \pm 2.0 vs. $97.5 \pm 2.7$, $p=0.798)$.

\section{DISCUSSION}

In the current study, no relationship was found between patient-reported outcome measures and objective measures following surgical treatment of ATR. Although significant residual functional limb asymmetry was detected in half of the patients, ATRS remained similar. Based on our findings, it can be proposed that ATRS does not reflect the actual functional status of the patients. Accordingly, there is an obvious need for better outcome measurement based on patient outcomes and objective functional measures.

In general, two criteria are used to evaluate the results after Achilles tendon injuries. The first depends on the physician's measurements through the physical examination and certain

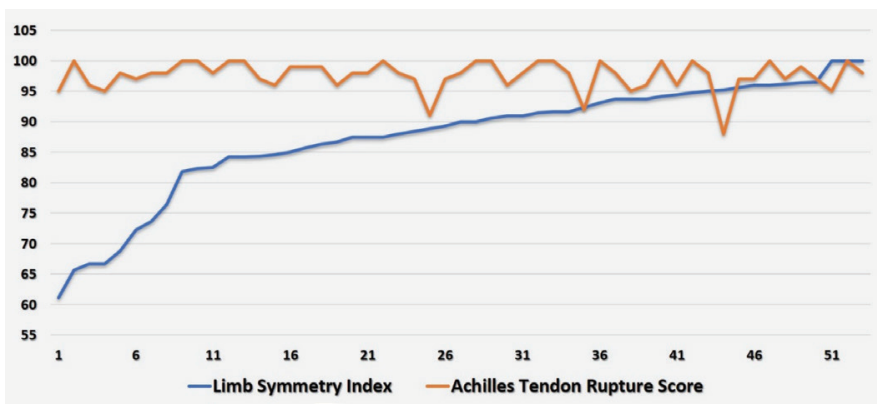

Figure 1. Graph showing the correlation between LSI and ATRS ATRS: Achilles tendon rupture score, LSI: Limb symmetry index

Table 2. Correlation between the ATRS score and calf atrophy and LSI

\begin{tabular}{|l|l|l|l|l|}
\hline & & ATRS & LSI & $\begin{array}{l}\text { Calf } \\
\text { atrophy }\end{array}$ \\
\hline \multirow{2}{*}{ ATRS } & Correlation coefficient & 1.000 & -0.090 & 0.042 \\
\cline { 2 - 5 } & Sig. (2-tailed) & - & 0.521 & 0.765 \\
\hline \multirow{2}{*}{ LSI } & Correlation coefficient & -0.090 & 1.000 & 0.169 \\
\cline { 2 - 5 } & Sig. (2-tailed) & 0.521 & - & 0.227 \\
\hline \multirow{2}{*}{$\begin{array}{l}\text { Calf } \\
\text { atrophy }\end{array}$} & Correlation coefficient & 0.042 & 0.169 & 1.000 \\
\cline { 2 - 5 } & Sig. (2-tailed) & 0.765 & 0.227 & - \\
\hline ATS
\end{tabular}

ATRS: Achilles tendon rupture score, LSI: Limb symmetry index, Sig: Significance specific tests. The other is a set of patient-reported outcome measurements (PROM) that has become increasingly important in recent years. ATRS is the most commonly used PROM after Achilles tendon injuries (15). However, the minimal detectable change value is 18.5 points for ATRS (13). Therefore, the ATRS has a low discriminative capacity.

Few published studies support our findings. Keene et al. (16) compared the potential benefit of platelet-rich plasma (PRP) injection with conservative treatment of ATR. There was no significant difference in ATRS between patients at the end of 24 weeks, but the LSI was significantly better in the PRP group. Westin et al. (17) evaluated the factors affecting the outcome one year after ATR in 391 patients. Although the older age at injury was a predictive factor for concentric Achilles power, no significant predictor was related to the ATRS. Brorsson et al. (18) examined calf muscle performance deficits seven years after ATR in 66 patients. Eighty-five percent of their patients scored more than 85 points on the ATRS, but only $29 \%$ of the patients had an LSI higher than $85 \%$ in calf muscle endurance and calf muscle concentric power. Kastoft et al. (19) compared early versus delayed weight-bearing in the non-operative treatment of acute ATR in 37 patients. At the end of 4.5 years, ATRS showed no association with heel-rise work or heel-rise height (19). Silbernagel et al. (20) examined the functional deficits in 78 patients with ATR using the heel-rise endurance test in the sixth and twelfth months. The authors found no significant correlations between ATRS and heel-rise endurance at the 6or 12-month evaluations (20). All these previous findings show that ATRS is not a sensitive outcome measure to evaluate the objective functional capacity of the Achilles tendon.

\section{Study Limitations}

The current study has some limitations. First, the functional capacity of the Achilles tendon was measured with a simple fatigue test. Although this is accepted as a good indicator of functional capacity, other sophisticated methods such as isokinetic muscle strength measurements were not available (21). The study assessed a relatively limited number of patients; however, the follow-up period was sufficiently long.

\section{CONCLUSION}

ATRS, which is the most commonly used PROM in ATR research, cannot show differences in the objective functional capacity following surgical treatment of the ATR. Future studies should focus on developing more accurate scoring systems that combine both objective and subjective measures. 


\section{Ethics}

Ethics Committee Approval: The Institutional Review Board at Antalya Training and Research Hospital approved the study protocol (approval date/issue: 4.3.2021/1.34).

Informed Consent: All patients provided consent to participate in the study.

Peer-review: Externally peer-reviewed.

\section{Authorship Contributions}

Surgical and Medical Practices: G.G., M.M.A., M.B.E., Ö.F.K., Ö.K., Concept: G.G., M.M.A., M.B.E., Ö.F.K., Ö.K., Design: G.G., M.M.A., M.B.E., Ö.F.K., Ö.K., Data Collection or Processing: G.G., M.M.A., M.B.E., Ö.F.K., Ö.K., Analysis or Interpretation: G.G., M.M.A., M.B.E., Ö.F.K., Ö.K., Literature Search: G.G., M.M.A., M.B.E., Ö.F.K., Ö.K., Writing: G.G., M.M.A., M.B.E., Ö.F.K., Ö.K.

Conflict of Interest: No conflict of interest was declared by the authors.

Financial Disclosure: The authors declared that this study received no financial support.

\section{REFERENCES}

1. Gass JD, Blodi BA. Idiopathic juxtafoveolar retinal telangiectasis. Update of classification and follow-up study. Ophthalmology 1993;100:153646.

2. Yannuzzi LA, Bardal AM, Freund KB, Chen KJ, Eandi CM, Blodi B. Idiopathic macular telangiectasia. Arch Ophthalmol 2006;124:450-60.

3. Tan GS, Kuehlewein L, Sadda SR, Sarraf D, Schwartz SD. Subretinal neovascularization in macular telangiectasia type 2: optical coherence tomographic angiography and treatment response. Retin Cases Brief Rep 2015;9:286-9.

4. Gass JD, Oyakawa RT. Idiopathic juxtafoveolar retinal telangiectasis. Arch Ophthalmol 1982;100:769-80.

5. Roisman L, Rosenfeld PJ. Optical Coherence Tomography Angiography of Macular Telangiectasia Type 2. Dev Ophthalmol 2016;56:146-58.

6. Jia Y, Bailey ST, Wilson DJ, Tan O, Klein ML, Flaxel CJ, et al. Quantitative optical coherence tomography angiography of choroidal neovascularization in age-related macular degeneration. Ophthalmology 2014;121:1435-44.

7. Jia Y, Tan O, Tokayer J, Potsaid B, Wang Y, Liu JJ, et al. Split-spectrum amplitude-decorrelation angiography with optical coherence tomography. Opt Express 2012;20:4710-25.

8. Balaratnasingam C, Yannuzzi LA, Spaide RF. Possible choroidal neovascularization in macular telangiectasia type 2. Retina 2015;35:2317-22.
9. Nowilaty SR, Al-Shamsi HN, Al-Khars W. Idiopathic juxtafoveolar retinal telangiectasis: a current review. Middle East Afr J Ophthalmol 2010;17:224-41.

10. Paunescu LA, Ko TH, Duker JS, Chan A, Drexler W, Schuman JS, et al. Idiopathic juxtafoveal retinal telangiectasis: new findings by ultrahighresolution optical coherence tomography. Ophthalmology 2006;113:4857.

11. Soheilian M, Tavallali A, Peyman GA. Identification of intraretinal neovascularization by high-speed indocyanine green angiography in idiopathic perifoveal telangiectasia. Ophthalmic Surg Lasers Imaging 2007;38:167-9.

12. Thorell MR, Zhang Q, Huang Y, An L, Durbin MK, Laron M, et al. Sweptsource OCT angiography of macular telangiectasia type 2. Ophthalmic Surg Lasers Imaging Retina 2014;45:369-80.

13. Gonzalez MA, Shechtman D, Haynie JM, Semes L. Unveiling idiopathic macular telangiectasia: clinical applications of optical coherence tomography angiography. Eur J Ophthalmol 2017;27:e129-e33.

14. Toto L, Di Antonio L, Mastropasqua R, Mattei PA, Carpineto P, Borrelli E, et al. Multimodal Imaging of Macular Telangiectasia Type 2: Focus on Vascular Changes Using Optical Coherence Tomography Angiography. Invest Ophthalmol Vis Sci 2016;57:0CT268-76.

15. Kearney RS, Achten J, Lamb SE, Plant C, Costa ML. A systematic review of patient-reported outcome measures used to assess Achilles tendon rupture management: what's being used and should we be using it? $\mathrm{Br}$ J Sports Med 2012;46:1102-9.

16. Keene DJ, Alsousou J, Harrison P, Hulley P, Wagland S, Parsons SR, et al. Platelet rich plasma injection for acute Achilles tendon rupture: PATH-2 randomised, placebo controlled, superiority trial. BMJ 2019;367:I6132.

17. Westin O, Svedman S, Senorski EH, Svantesson E, Nilsson-Helander K, Karlsson J, et al. Older Age Predicts Worse Function 1 Year After an Acute Achilles Tendon Rupture: A Prognostic Multicenter Study on 391 Patients. Orthop J Sports Med 2018;6:2325967118813904.

18. Brorsson A, Grävare Silbernagel K, Olsson N, Nilsson Helander K. Calf Muscle Performance Deficits Remain 7 Years After an Achilles Tendon Rupture. Am J Sports Med 2018;46:470-7.

19. Kastoft R, Bencke J, Speedtsberg MB, Penny JØ, Barfod K. Early weightbearing in nonoperative treatment of acute Achilles tendon rupture did not influence mid-term outcome: a blinded, randomised controlled trial. Knee Surg Sports Traumatol Arthrosc 2019;27:2781-8.

20. Silbernagel KG, Nilsson-Helander K, Thomeé R, Eriksson BI, Karlsson J. A new measurement of heel-rise endurance with the ability to detect functional deficits in patients with Achilles tendon rupture. Knee Surg Sports Traumatol Arthrosc 2010;18:258-64.

21. Todorov A, Schaub F, Blanke F, Heisterbach P, Sachser F, Gösele A, Majewski M. Clinical assessment is sufficient to allow outcome evaluation following surgical management of Achilles tendon ruptures. Muscles Ligaments Tendons | 2015;5:68-72. 